\title{
Author Correction: Next-generation influenza vaccines: opportunities and challenges
}

Chih-Jen Wei, Michelle C. Crank, John Shiver, Barney S. Graham, John R. Mascola and Gary J. Nabel(1)

Nature Reviews Drug Discovery (2020) https://doi.org/10.1038/s41573-019-0056-x Published online 14 February 2020

In the subsection on post-licensure considerations, the authors wish to clarify that accelerated licensure granted for high-dose trivalent influenza vaccine was independent of the $2009 \mathrm{H} 1 \mathrm{~N} 1$ outbreak, and the randomized controlled trial in approximately 31,000 adults 65 years of age and older showed that the high-dose influenza vaccine demonstrated clear superior efficacy relative to the standard-dose vaccine ${ }^{210}$. Text in this subsection has been modified accordingly.

https://doi.org/10.1038/s41573-020-0066-8 I Published online 13 March 2020

(c) Springer Nature Limited 2020

\section{Publisher Correction: ASPI: a public-private partnership to develop treatments for autism}

Seth Ness, Gahan Pandina, Shyla Jagannatha, Kyle Wathen, Abigail Bangerter, Nikolay V. Manyakov, Robert Hendren, Bennett Leventhal, Declan Murphy, Geraldine Dawson, Wayne C. Drevets and Husseini K. Manji

Nature Reviews Drug Discovery 19, 219-220 (2020) https://doi.org/10.1038/d41573-020-00012-4

Published online 22 January 2020

The surname for Wayne C. Drevets was incorrect in the online pdf and print versions, and the online pdf has now been corrected.

https://doi.org/10.1038/s41573-020-0069-5 I Published online 6 May 2020

(c) Springer Nature Limited 2020 